\title{
Surgical Management of Mandibular Ameloblastoma and Immediate Reconstruction with Nonvascularized Bone Graft and Hyperbaric Oxygen Therapy
}

\author{
Tratamiento Quirúrgico de Ameloblastoma Mandibular y la Reconstrucción \\ Inmediata con Injerto Oseo Libre y Terapia con Oxígeno Hiperbárico
}

Gabriel Pires Pastore;; Ivan Solani Martins*; Douglas Rangel Goulart*; Alexandre Javaroni Prati”; Márcio de Moraes ${ }^{* * *}$; Patrícia Radaic Pastore* \& Manuel Claro de Toledo****

PASTORE, G. P.; MARTINS, I. S.; GOULART, D. R.; PRATI, A. J.; DE MORAES M.; PASTORE, P. R. \& DE TOLEDO, M. C. Surgical management of mandibular ameloblastoma and immediate reconstruction with nonvascularized bone graft and hyperbaric oxygen therapy. Int. J. Odontostomat., 10(3):409-417, 2016.

\begin{abstract}
Extensive resection of tumor often results in bone and soft tissue defects that cause functional and esthetic consequences. The reconstructive surgery is extremely important for the rehabilitation of these patients. The purpose of this study is to report on the use of Hyperbaric Oxygen therapy (HBO) in the case of a large ameloblastoma treated with segmental resection and reconstructed immediately with nonvascularized bone graft (NVBGs) from iliac crest. A 41-year-old woman was referred to our department because of paresthesia of the inferior alveolar nerve and history of swelling in the molar and ramus region of the left mandible. Panoramic radiograph depicting well-defined multilocular radiolucency extending from second premolar region to the left ramus region. An incisional biopsy confirms the diagnosis of solid ameloblastoma. The treatment of choice was segmental mandibular resection and immediate mandibular reconstruction using NVBGs from iliac crest, followed by removal of internal fixation and placement of dental implants with immediate loading. The patient received preoperative HBO (a 90-min session at 2.2-2.4 atmospheres, five times per week for two weeks, for a total of up to 10 sessions). Postoperative HBO (10 further 90-min sessions) was administered within 2 weeks. The patient received rehabilitation with a mandibular implant-supported fixed complete dental prosthesis. The present study showed successful management of mandibular ameloblastoma that associated extensive surgery, immediate reconstruction with NVBGs from iliac crest, hyperbaric oxygen therapy and dental implants. These combined procedures allowed removal of lesion and reestablishment of mandibular contour and function.
\end{abstract}

KEY WORDS: bone transplantation, hyperbaric oxygenation, mandible, odontogenic tumors.

\section{INTRODUCTION}

Ameloblastoma is a locally aggressive tumor that, if not treated, could gain enormous size and cause severe facial disfigurement and functional impairment (Sönmez et al., 2012). The treatment of choice for this neoplasm (solid and multicystic) is resection in the form of segmental or marginal resection (Carlson \& Marx, 2006).

Segmental resection of mandible may cause considerable morbidity. Disruption of muscular attachments and loss of innervation (sensory and mo- tor nerves) may cause problems with mastication, swelling and speech (van Gemert et al., 2009). It often involves the loss of an important bone segment that includes teeth that compromises chewing (Oliveira et al., 2013).

The mandibular reconstruction is extremely important for the rehabilitation of the patient who underwent bone resection. The restoration of mandibular function and facial esthetics is essential to maintain the quality of life (Oliveira et al.). This can be

* Department of Oral and Maxillofacial Surgery, Paulista University, São Paulo, Brazil.

** Piracicaba Dental School - State University of Campinas - UNICAMP, São Paulo, Brazil.

** Department of Oral Diagnosis, Oral and Maxillofacial Division, Piracicaba Dental School,State University of Campinas,São Paulo, Brazil.

*t***oral and Maxillofacial Surgeon - Amaral Carvalho Hospital, São Paulo, Brazil. 
performed immediately or delayed in relation to tumor resection procedure. Both vascularized bone flaps (VBF) and nonvascularized bone grafts (NVBGs) are generally accepted treatment strategies for mandibular reconstruction (van Gemert et al.).

Some circumstances may influence the choice between a VBF or na NVBG, the patient medical condition, age, quality of vessels, vascularity of recipient site, expected donor-site morbidity (van Gemert et al.) The nonvascularized iliac crest graft seems to be reasonably reliable treatment option for reconstruction of mandibular defects up to about 5-6 $\mathrm{cm}$ in size (Handschel et al., 2011).

Hyperbaric oxygen therapy ( $\mathrm{HBO}$ ) has been used as an adjunctive treatment in mandibular reconstruction mainly in irradiated patients (Foster et al., 1999; Handschel et al.; Oliveira et al.; Peleg \& Lopez, 2006; van Gemert et al.). There were some changes in the wound healing using $\mathrm{HBO}$, which includes controlling vascular permeability, decreasing tissue edema, and reducing inflammatory damage, with positive results in bone neoformation. HBO might be valuable for bone regeneration (Rocha et al., 2015). The purpose of this study is report the use HBO in a case of a large ameloblastoma treated with segmental resection and reconstructed immediately with nonvascularized bone graft from iliac crest.

\section{CASE REPORT}

A 41-year-old woman was referred to our department because of paresthesia of the inferior alveolar nerve and history of swelling in the molar and ramus region of the left mandible. In the physical examination, she presents swelling extended from premolars to third molar region. The patient presented facial asymmetry related to an increase of volume at the left mandibular body. Panoramic radiograph depicting well-defined multilocular radiolucency extending from second pre-molar region to the left ramus region (Fig. 1).

An incisional biopsy confirms the diagnosis of solid ameloblastoma. Computed Tomography images showed a multilocular mass in the whole left mandibular body with lingual cortical erosion (Fig. 2). The treatment of choice was segmental mandibular resection and immediate mandibular reconstruction using NVBGs from left iliac crest.

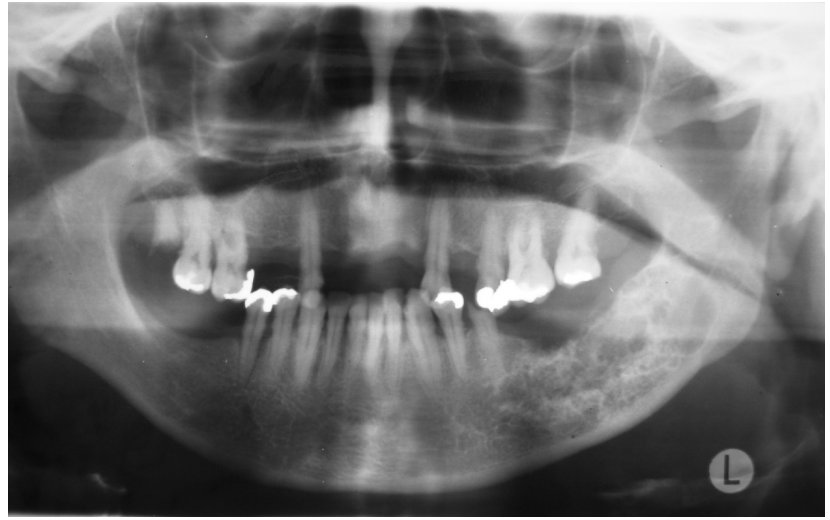

Fig. 1. Panoramic radiograph depicting a large ameloblastoma of the left mandible.

Adjunctive treatment with hyperbaric oxygen therapy (HBO) was performed. Patient received preoperative HBOT (a 90-min session at 2.2-2.4 atmospheres, five times per week for two weeks, for a total of up to 10 sessions). Postoperative HBOT (10 further 90-min sessions) was administered within 2 weeks. The patient was submitted to a surgery under general anesthesia. Through a submandibular approach, the tumor was resected with margin of 1 $\mathrm{cm}$, from ramus to parasymphisis to the mandibular ramus. The immediate reconstruction of the defect was performed by using NVBGs from left iliac crest. Surgical approach and exposure of mandible were followed by adaption of a reconstruction plate to maintain the mandibular perimeter during resection (Figs. 3-4).

The immediate postoperative follow-up was free from complications. Six-month follow-up panoramic radiograph of the resection and bone graft depicted good bone density and bone height achieved.

Six months after the reconstruction the titanium plate and screws were removed. In this procedure there was an unexpected fracture at left mandibular condyle. The initial plate was removed and the fracture was reduced and fixed (Fig. 6). The remaining teeth showed periodontal disease and in accordance with the patient, teeth extractions were performed in order to allow mandibular implant-supported fixed complete dental prosthesis. After four months, a new surgical procedure was performed and the plate of left condyle was removed and five dental implants were inserted in mandible (External Hex connection platform 4.1 and a length of $13 \mathrm{~mm}$ ). The prosthetic rehabilitation is immediately using a screw-retained fixed prosthesis $72 \mathrm{~h}$ after surgery (Fig. 7). Figure 8 shows 1-year follow-up panoramic radiograph. The patient was followed up for 

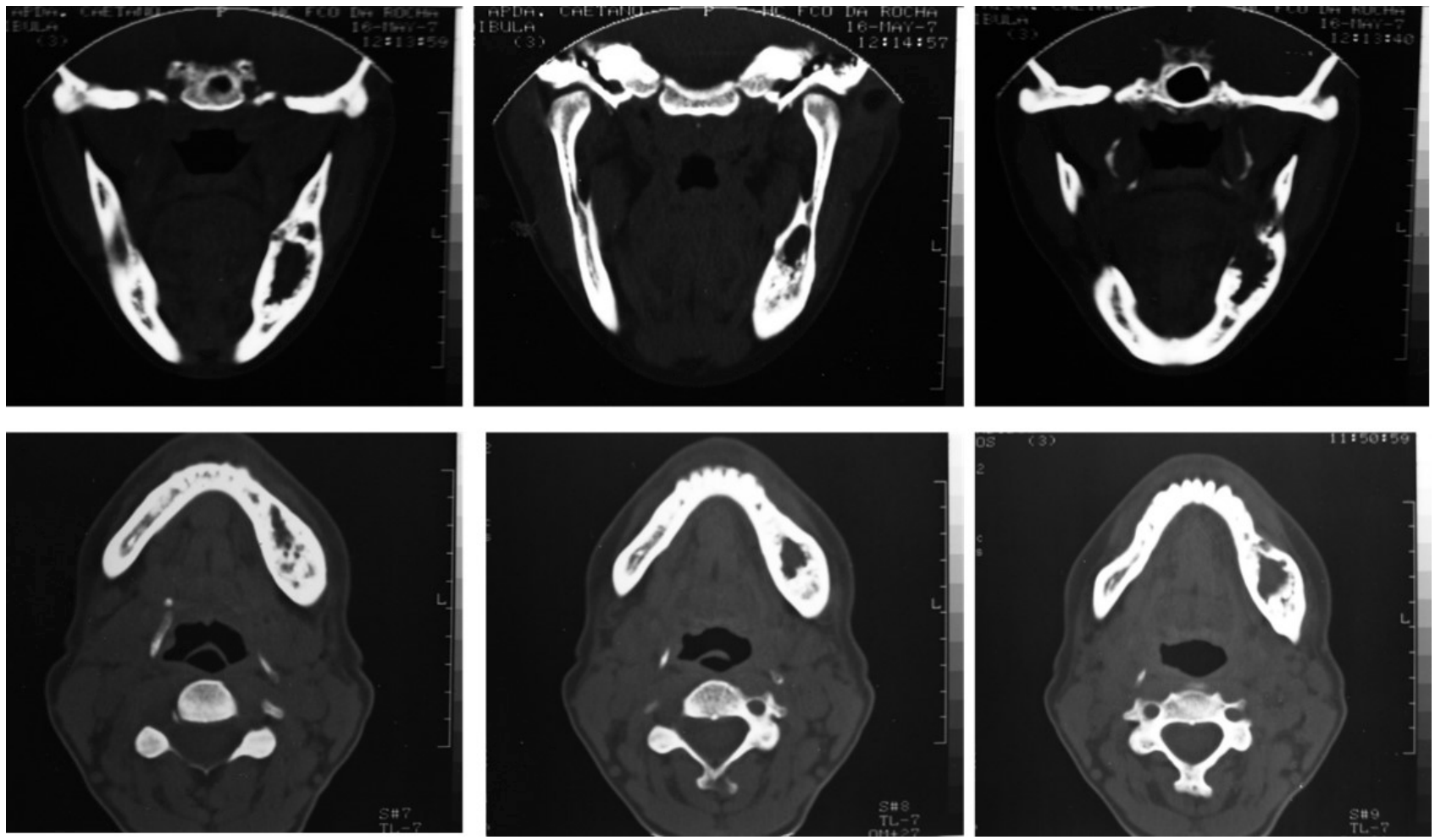

Fig. 2. Preoperative CT scan of the mandible showing erosion at lingual cortical of left mandibular body.
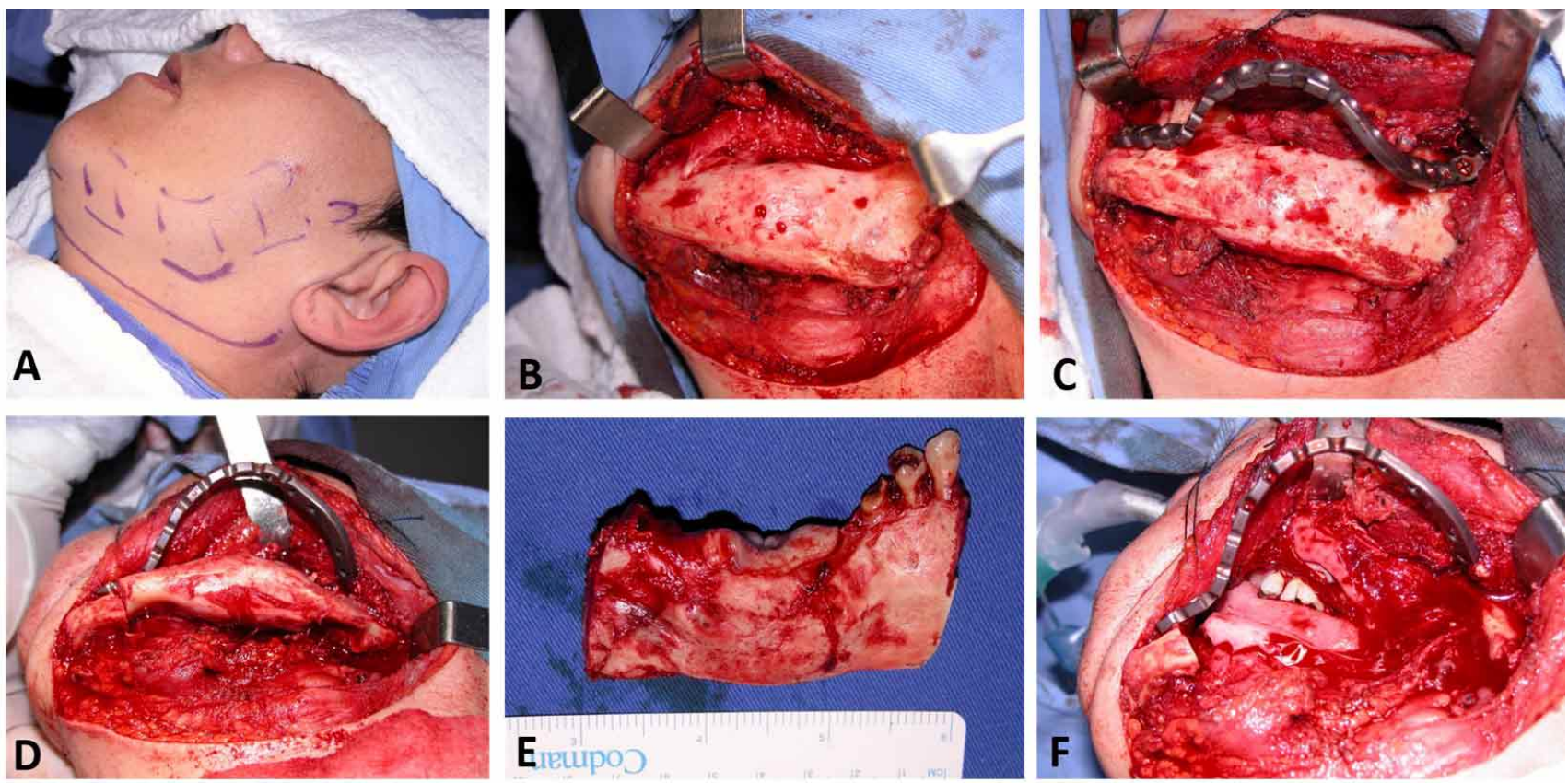

Fig. 3. A. Design of the submandibular approach; B. Exposure of the mandible C-D. A reconstruction plate was adapted to maintain the mandibular perimeter during resection; E. Resection specimen of an ameloblastoma with $1.0 \mathrm{~cm}$ margins in bone and overlying periosteum as an anatomic barrier; F. Intraoperative view of resected tumor and mandibular defect.

two years without complications. The contour and function of the mandible was reestablished. One-year follow-up panoramic radiograph depict bone graft with good density and no significant marginal bone loss at implants (Fig. 8). 

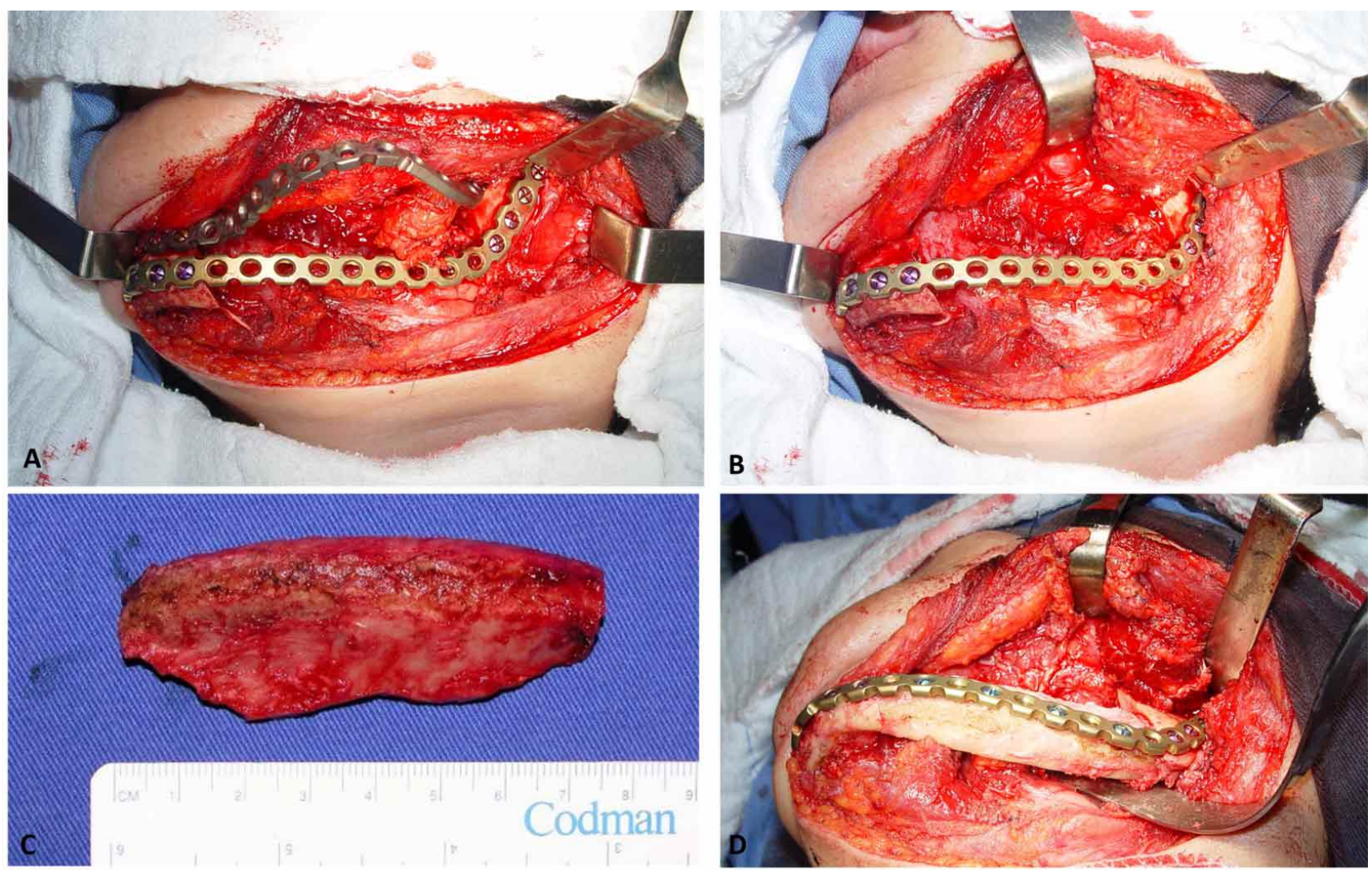

Fig. 4 A. The reconstruction of a tumor-related segment defect was accomplished with a rigid titanium plate; B. initial reconstruction plate was removed; C. Nonvascularized bone graft from iliac crest; D. Iliac crest bone graft in position fixed with locking screws.

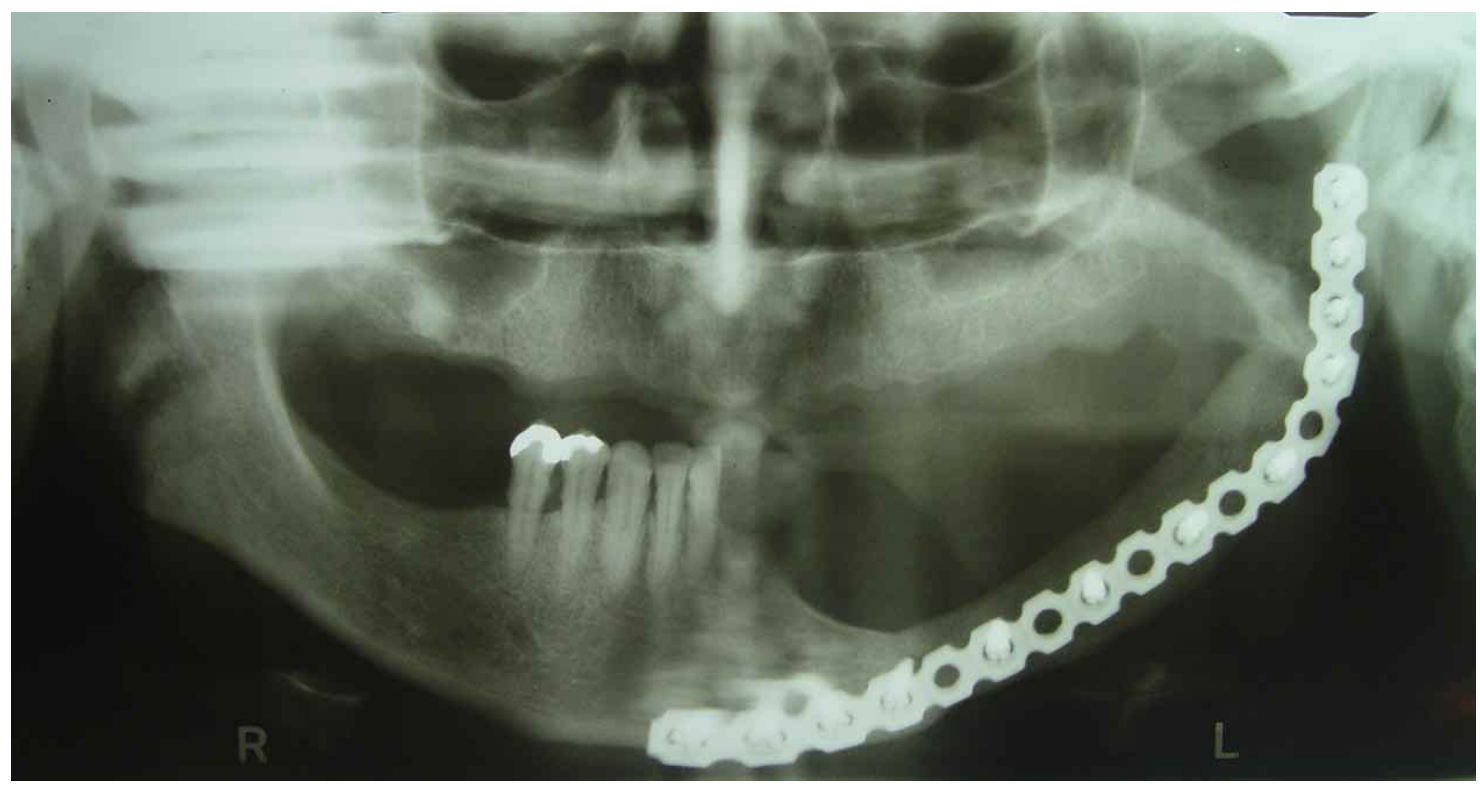

Fig. 5 Six-month follow-up panoramic radiograph of the resection and bone graft depicts good bone density and bone height achieved. 
PASTORE, G. P.; MARTINS, I. S.; GOULART, D. R.; PRATI, A. J.; DE MORAES M.; PASTORE, P. R. \& DE TOLEDO, M. C. Surgical management of mandibular ameloblastoma and immediate reconstruction with nonvascularized bone graft and hyperbaric oxygen therapy. Int. J. Odontostomat., 10(3):409-417, 2016.

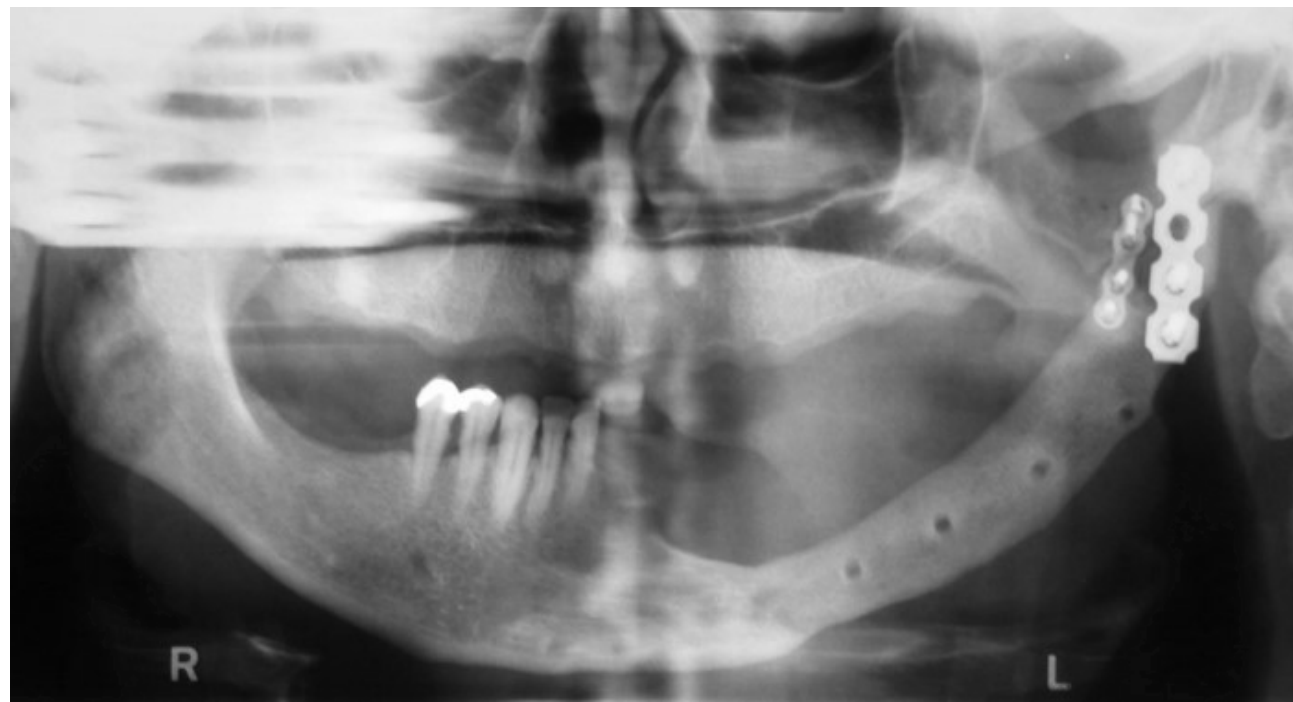

Fig. 6 Postoperative panoramic radiograph of reconstruction plate and screws removal showing left mandibular condyle fracture.
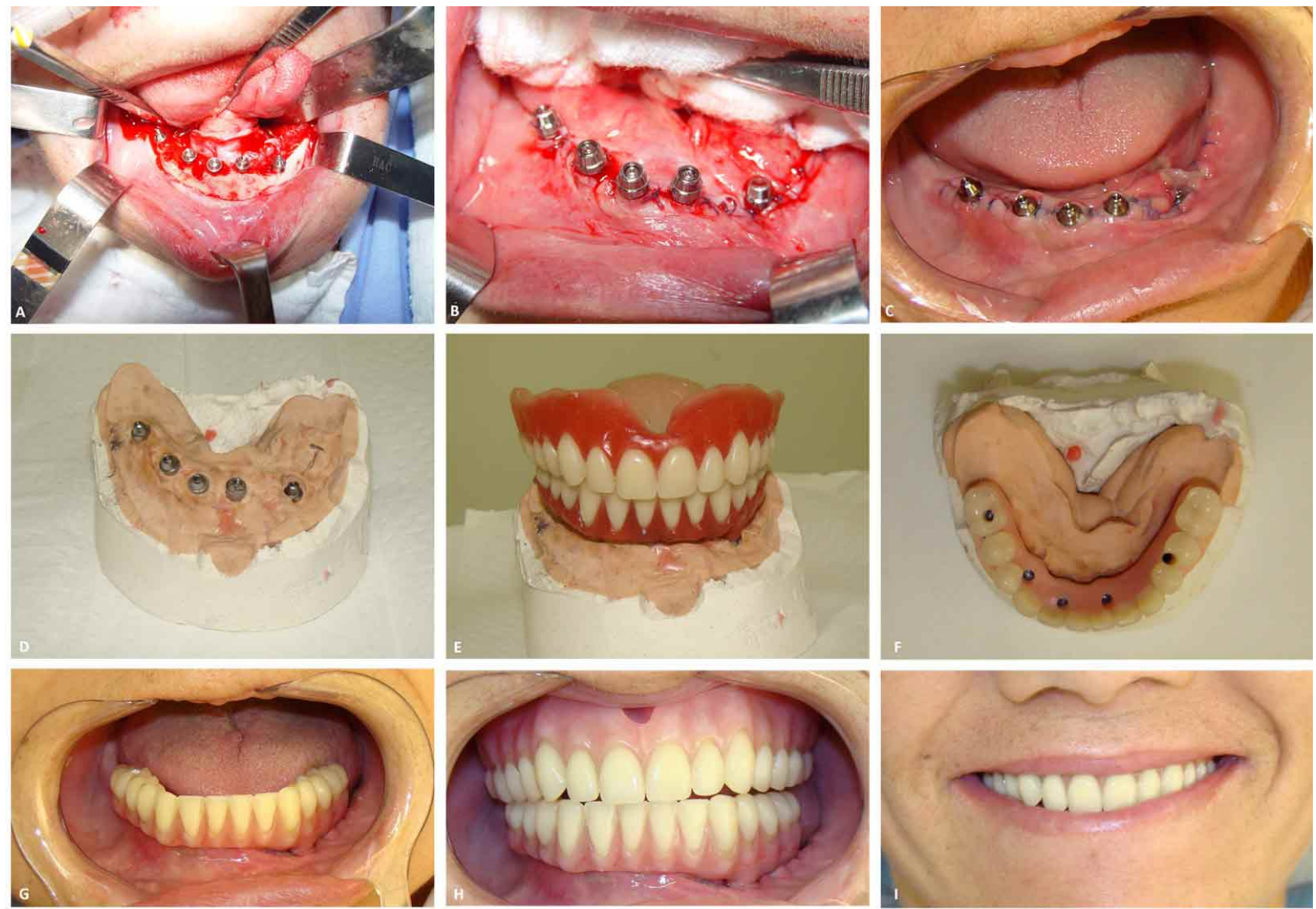

Fig. 7. A-B. Intraoperative view of dental implants in mandible; C. Would healing Implant-supported, fixed prosthetic rehabilitation; D. Cast model showing dental implant distribution within mandibular perimeter; E. Prosthetic planning of occlusion that include the replacement of maxilar denture; $\mathrm{G}-\mathrm{H}$. The screw-retained fixed prosthesis in this case is seen to restore occlusion and replace the teeth lost due to the tumor resection; I. Final appearance of patient smile after mandibular reconstruction and rehabilitation. 


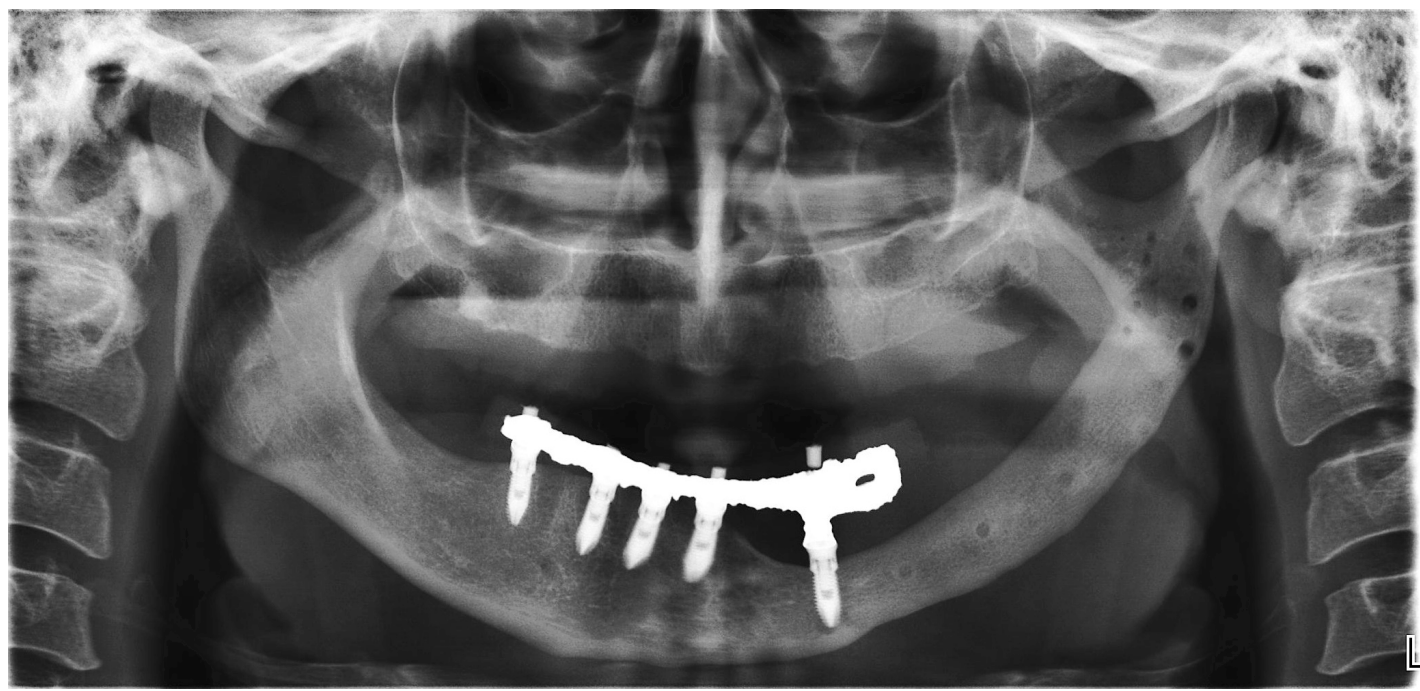

Fig. 8 One-year follow-up panoramic radiograph of the dental implants placement depicts good bone density and no significant marginal bone loss.

\section{DISCUSSION}

Extensive resection of tumor often results in bone and soft tissue defects that cause functional and esthetic consequences (Navarro Cuellar et al., 2014). Regarding treatment of jaw neoplasms, the success was defined as maintenance of bone continuity and stability, and absence of infection 1 year after reconstruction upon clinical and radiographic examination (van Gemert et al.). There are others surgical interventions reported in the treatment of ameloblastoma, that are named as "conservative" therapy in the form of enucleation and enucleation and curettage (Carlson \& Marx). However, it is questionable, why surgeons would provide conservative therapy for an aggressive neoplasm. The primary curative therapy is necessary (Carlson \& Marx). The present case report showed a successful management of mandibular ameloblastoma using bone resection and immediately reconstruction using NVBG from iliac crest. In this case, the linear bone margin adopted was $1 \mathrm{~cm}$, the most appropriated linear margin is still debated, but 1 to 1.5 $\mathrm{cm}$ seems to provide a margin-free specimen (Carlson \& Marx). It is important emphasize that the reconstruction was considered functionally complete if prosthetic rehabilitation was accomplished or if there was a sufficient remaining dentition for mastication (van Gemert et al.) Thus, the case reported present treatment until final rehabilitation of patient.
The choice of reconstruction a large mandibular gap using NVBG was related to authors experience and the lack of expert team in VBF. Other factors that contribute were no history of local irradiation and location of bone defect. Nonvascularized iliac crest bone grafts for segmental reconstruction of the mandible was usually used on the condition that the defect is truly lateral and only an extraoral approach is used (van Gemert et al.). VBF are indicated in most cases of mandibular reconstruction; Regarding the amount and durability of supplied bone, VBF seems to provide superior results when compared to NVBGs and alloplastic bone substitutes (Sönmez et al.). The lack of soft tissue is a firm exclusion criterion for the use of nonvascularized bone grafts (Handschel et al.). It remains unclear which defect size is most suitable for NVBGs, it seems to be a reasonably reliable treatment option for reconstruction of mandibular defects up to 5-6 cm in size (Handschel et al.), however there are cases of greater bone defects successfully treated.

Other important questions when resection of bone tumors in mandible is planned, is when reconstruction should be performed. The appropriate time point for reconstruction (immediately and secondary) could vary according to types of bone transplants which is also currently debated (Handschel 
et al.). Whenever possible, immediate reconstruction should be performed. It decreases the number of surgeries and patient exposure to general anesthesia. Later reconstructions are more difficult due to retraction and fibrosis of soft tissue. Redundant soft tissue is often present, it is essential to immediate bone reconstruction (Simon et al., 2013). In this case reported the immediate reconstruction was planned associated to $\mathrm{HBO}$ and was successfully performed.

There is several HBO therapy protocol, most of authors used this adjunctive therapy for patients who had been irradiated prior to reconstruction (van Gemert et al.). Hyberbaric oxygen therapy seems to be the only known treatment which is able to reverse in part, the radiations changes in the tissue (Handschel et al.). The protocol used in this study is in accordance with Germet et al. (2009) that used 20 sessions of hyperbaric oxygen therapy, 10 prior to surgery and 10 postoperatively. After HBO these patients received intravenous antibiotics for at least 10 days postoperatively (van Gemert et al.). Oliveira et al., reported a different $\mathrm{HBO}$ therapy protocol that consists in 10 sessions prior to reconstructive surgery and 40 subsequent sessions. (Oliveira et al.).

The cumulative effect of $\mathrm{HBO}$ could restore the cellularity and vascularity of radiated tissue to approximately 70 to $80 \%$ of normal. These improvements will favorably support any surgical attempts to surgically treat osteoradionecrosis and eventually bone reconstruction (Peleg \& Lopez). HBO treatment clearly accelerates the histologic process underlining the initial events of bone repair. It stimulates initial cell proliferation and directly enhances osteogenic differentiation of osteoblasts (Rocha et al.). The bactericidal and bacteriostatic properties of $\mathrm{HBO}$ could prevent infection in reconstructed sites (Oliveira et al.). For these reasons, the author of this case report believes that large mandibular defects could be reconstructed using NVBGs associated $\mathrm{HBO}$, and even small defects can benefit from its use.

Gemert et al., identified that patients who irradiated has less complications than nonirradiated patients (19\% x $47 \%)$. All irradiated patients received $\mathrm{HBO}$ and intravenous antibiotics. There are several confounding variables that could be involved in failure of bone grafts, however the overall success rate could be related to $\mathrm{HBO}$; it is an important adjunct therapy in the success of treatment, however more studies are needed to establish the best modality of rehabilitation (Oliveira et al.).
The failure of mandibular reconstruction was associated with symphyseal involvement and intraoral approach, and smoking. Most of the complications are located at recipient-site, occurs at first year of postoperative (van Gemert et al.). The presence of a dead space and a lengthy surgical procedure may also increase the risk of wound infection and dehiscence (van Gemert et al.). If there is a communication of the wound with oral cavity preoperatively, the mucosa should be closed with watertight sutures before placement of the bone graft (van Gemert et al.). In this case reported, there is no complication related to donor and recipient-site. An unexpected left condylar fracture occurs in the removal of plate and screws, this case did not present major complications for the patient. However, it delayed the placement of dental implants and mandibular rehabilitation.

Rigid fixation of the grafts seems essential as healing is impaired by movements of the grafts and can result in neoarthrosis or infection (van Gemert et al.). Some author advocated the use of miniplates to fixate bone graft, however the reconstruction plates should be used when osteotomies in the iliac bone was required to gain curvature in hemi-mandibular defects (Sönmez et al.). In this case reported, a rigid internal fixation was used in order to prevent graft movement, and the use of locking plates and screws allowed the integration of bone graft without screw loosening.

Patients that were submitted to mandibular resection and reconstruction are benefited by rehabilitation with the use of an implant supported prosthetic device, which improves aesthetics and function (Simon et al.). The placement of dental implants is related to amount and vascularization of bone graft. The iliac crest flap enables reconstruction of mandibular bone width and height, thus the immediate placement of dental implants. It is mainly cancellous bone that is rich in blood supply (Navarro Cuellar et al.). The immediate placement of implants enables faster rehabilitation of the prosthesis, fewer surgical interventions. It is mandatory in patients who will receive radiation therapy, because the effects of radiation in bone occurs after 6-8 months, that enables the phases of osseointegration osteophyllic and osteoconductive (Navarro Cuellar et al.). When dental implants are placed immediately during mandibular reconstruction the coordination between the screw, plates fixation and implant placement is possible. However, this procedure is less precise. Implant misalignment could imply in prosthesis 
rehabilitation: fixed or removable (Foster et al.). Thus, a surgical procedure to removal plates and screws are not required. When NVBGs is performed the implant placement is usually delayed until the integration of bone graft was completed.

Foster et al., performed 75 consecutive cases of mandibular reconstruction using free bone flaps (26) and vascularized bone flaps (49). A total of 104 endosseous implants were placed (NVBG: 8 patients, 33 implants; VBF: 14 patients; 71 implants). In $54 \%$ of VBF implants were placed immediately. The VBF showed greater implant success compared to NVBG: $82 \%(27 / 33)$ versus $99 \%$ (70/71) VBG, with statistical significant difference $(p<0.001)$. This study is the first to compare bone healing and osseointegrated implant success between these two methods of mandibular reconstruction. The significant difference in the osseointegration rates could be related structure of bone graft and level of osteoblastic activity throughout the graft. In the NVBG the osteoblastic activity is variable due to an uneven distribution of blood supply (Foster et al.).

In this case reported, dental implants were placed eight months after mandibular reconstruction, it was delayed due to mandibular left condyle fracture. However, the immediate loading prosthetic rehabilitation was achieved due to good primary implant stability that accelerated final rehabilitation. When NVBGs are planned, the reconstruction is usually performed 3-4 months after mandibular resection particularly in the cases of malignant disease, and immediate implant placement is not an option, it is placed
5 to 6 months after reconstruction, followed by more 6 months for osseointegration. Prosthetic rehabilitation requires another 4-5 months. The average total time required to full dental restoration using NVBGs is 21 months or longer (Foster et al.). The average time to full dental restoration using VBF is usually 10 months: 4-6 months for osseointegration and 4-5 months for prosthetic rehabilitation (Foster et al.). In this case reported, the overall time required to final rehabilitation was approximately 10 months after mandibular resection, it was achieved due to the decision to perform immediate reconstruction of mandibular gap and using Immediate Loading of Implant-Supported Fixed Complete mandibular denture.

Treatment of ameloblastoma poses a challenge for the surgeon, successful management requires adequate functional and aesthetically acceptable reconstruction of the residual defect. The role of size of bone defect and the importance of HBO therapy should be elucidated.

\section{CONCLUSION}

The present study showed successful management of mandibular ameloblastoma that associated extensive surgery, immediate reconstruction with nonvascularized bone graft from iliac crest, hyperbaric oxygen therapy and dental implants. These combined procedures allowed removal of lesion and reestablishment of mandibular contour and function.

PASTORE, G. P.; MARTINS, I. S.; GOULART, D. R.; PRATI, A. J.; DE MORAES M.; PASTORE, P. R. \& DE TOLEDO, M. C. Tratamiento quirúrgico de ameloblastoma mandibular y la reconstrucción inmediata con injerto oseo libre y terapia con oxígeno hiperbárico. Int. J. Odontostomat., 10(3):409-417, 2016.

RESUMEN: La resección extensa de un tumor a menudo da lugar a defectos del hueso y de los tejidos blandos, que causan consecuencias funcionales y estéticas. La cirugía reconstructiva es extremadamente importante para la rehabilitación de estos pacientes. El propósito de este estudio fue informar sobre el uso de la terapia de oxígeno hiperbárico (HBO) en un caso de un ameloblastoma de gran tamaño, tratado con resección segmentaria y reconstruido inmediatamente con injerto óseo no vascularizado (IONV) de la cresta ilíaca. Una mujer de 41 años fue derivada a nuestro servicio por parestesia del nervio alveolar inferior e historia de hinchazón en la región molar y ramina de la mandíbula izquierda. Radiografía panorámica que muestra una radiolucencia multilocular bien definida que se extiende desde la segunda región pre-molar hasta la región de la rama izquierda. Una biopsia incisional confirma el diagnóstico de ameloblastoma sólido. El tratamiento de elección fue la resección mandibular segmentaria y la reconstrucción mandibular inmediata mediante IONV de cresta ilíaca, seguido de la eliminación de la fijación interna y la colocación de implantes dentales con carga inmediata. La paciente recibió OHB preoperatoria (una sesión de 90 minutos a 2.2-2.4 atmósferas, cinco veces por semana durante dos semanas, para un total de hasta 10 sesiones). La OHB postoperatoria (10 sesiones adicionales de 90 minutos) se administró en 2 semanas. La paciente recibió rehabilitación con una prótesis dental fija con implante mandibular. El presente estudio mostró un manejo exitoso del ameloblastoma mandibular asociado a una cirugía extensa, reconstrucción inmediata con IONV de cresta ilíaca, oxigenoterapia hiperbárica e implantes dentales. Estos procedimientos combinados permitieron la extirpación de la lesión y el restablecimiento del contorno y la función mandibular.

PALABRAS CLAVE: trasplante óseo, oxígeno hiperbárico mandíbula, tumores odontogénicos. 
PASTORE, G. P.; MARTINS, I. S.; GOULART, D. R.; PRATI, A. J.; DE MORAES M.; PASTORE, P. R. \& DE TOLEDO, M. C. Surgical management of mandibular ameloblastoma and immediate reconstruction with nonvascularized bone graft and hyperbaric oxygen therapy. Int. J. Odontostomat., 10(3):409-417, 2016.

\section{REFERENCES}

Carlson, E. R.; Marx, R. E. The ameloblastoma: Primary, curative surgical management. J. Oral Maxillofac. Surg., 64(3):484-94, 2006.

Foster, R. D.; Anthony, J. P.; Sharma, A.; Pogrel, M. A. Vascularized bone flaps versus nonvascularized bone grafts for mandibular reconstruction: An outcome analysis of primary bony union and endosseous implant success. Head Neck, 21(1):66-71, 1999.

Handschel, J., Hassanyar, H., Depprich, R. A., Ommerborn, M. A., Sproll, K. C., Hofer, M.; Naujoks, C. Nonvascularized iliac bone grafts for mandibular reconstruction - Requirements and limitations. In Vivo, 25(5):795-99, 2011.

Navarro Cuellar, C.; Caicoya, S. J.; Acero Sanz, J. J.; Navarro Cuellar, I.; Muela, C. M.; Navarro Vila, C. Mandibular reconstruction with iliac crest free flap, nasolabial flap, and osseointegrated implants. J. Oral Maxillofac. Surg., 72(6):1-15, 2014.

Oliveira, M. T; Rocha, F. S.; de Paulo, L. F.; Rodrigues, A. R.; Zanetta-Barbosa, D. The approach of ameloblastoma of the mandible: a case treated by hyperbaric oxygen therapy and bone graft reconstruction. Oral Maxillofac. Surg., 17(4):311-4, 2013.

Peleg, M.; Lopez, E. A. The Treatment of Osteoradionecrosis of the Mandible: The Case for Hyperbaric Oxygen and Bone Graft Reconstruction. J. Oral Maxillofac. Surg., 64(6):956-60, 2006.

Rocha, F. S., Gomes Moura, C. C., Rocha Rodrigues, D. B., Zanetta-Barbosa, D., Nakamura Hiraki, K. R., \& Dechichi, P. Influence of hyperbaric oxygen on the initial stages of bone healing. Oral Surg. Oral Med. Oral Pathol. Oral Radiol., 120(5):581-87, 2015.

Simon, E. N.; Merkx, M. A.; Kalyanyama, B. M.; Shubi, F. M.; Stoelinga, P. J. Immediate reconstruction of the mandible after resection for aggressive odontogenic tumours: A cohort study. Int. J. Oral Maxillofac. Surg., 42(1):106-12, 2013.

Sönmez, E.; Tözüm, T. F.; Tulunoglu, I.; Sönmez, N. S.; Safak, T. Iliac crest flap for mandibular reconstruction after advanced stage mandibular ameloblastoma resection. Ann. Plast. Surg., 69(5):529-34, 2012.

van Gemert, J. T.; van Es, R. J.; Van Cann, E. M.; Koole, R. Nonvascularized Bone Grafts for Segmental Reconstruction of the Mandible-A Reappraisal. J. Oral Maxillofac.Surg,, 67(7):1446-52, 2009.
Correspondence to:

Prof. Gabriel Pastore

Rua Dr. Bacelar, 1212

Vila Clementino

Postal Code: 04026-002

São Paulo - SP

BRAZIL

E-mail: pastore@institutovitta.org.br douglasrgoulart@gmail.com

Received: 11-03-2016

Accepted: 17-10-2016 